\title{
DIREITO CIVIL
}

\author{
E! necessaria a. hasta publica para \\ a venila de immoveis pertencentes a me- \\ nores sob o.patrio poder?
}

Năo se confunde esta questão com a de saber se é necessarịa a hasta publica para a alienação de bens de orfams. $\mathrm{O}$ nosso fito é verificar exclusivamente se a lei exige a praça para a transferencia de bens de raiz, de que são proprietarios menores que têm pae vivo, sob cujo poder estão.

As duas hypotheses são muito distinctas, especialmente quando se attende á natureza dos interesses que importa acautelar. O patrimonio do orfam está exposto aos conluios do tutor com terceiros para a acquisição dos bens da tutela por baixo preço. Demais, ao tutor é indifferente não raro que a venda se faça por mais ou por menos. O patrimonio do menor sob o patrio poder está exposto sobretudo á dilapidação do pae, que, na qualidade de usufructuario, é proprietario dos bens fungiveis do usufructo, com a obrigação de restituir bens da mesma qualidade em egual quantidade, ou o seu valor (Carlos de Carvalho, Nova Consolidação, art. 579); e consequentemente, podendo dispôr do producto da venda dos immoveis dọ 
filho menor, tem 'todo o interesse em que se faça a alienação pelo mais alto preço. De que serviria vender o predio pelo preço maximo, em hasta publica, se o dinheiro é entregue ao pae como usufructuario e administrador dos bens do filho? Vê-se, pois, que, além do interesse do pae coincidir com o do filho quanto á elevação do preço (o que não se dá no caso dọ tutor), a hasta publica de modo algum garantiria a conservação do patrimonio do filho. Os paes, em geral, têm no seu coração um tribuno eloquentissimo, que a todos os momentos pleitêa a causa dos tilhos. Quando, por excepção, essa voz emmudece, e os paes abusivamente querem aproveitar.se dos bens dos filhos, de nada vale a hasta publica: o remedio é outro, e consiste em vedar a alienação dos immoveis sob qual. quer fórma, ou em medidas ainda mais graves, permittidas pelo direito patrio (Ord., liv. $3 .^{\circ}$, tit. $9 .^{\circ}, \& 4 .^{\circ}$, C. DE Carvalho, obra citada, art. I 579).

A differença entre a venda de immoveis de oxfams e a venda de immoveis de menor sob o patrio poder está claramente consagrada pela lei. A Ord., liv. r. ${ }^{\circ}$, tit. $88, \S \S 22$ a 30 , trata dos bens dos orfams. Obriga os tutores, ou manda que os juizes obriguem 'os tutores a arrendarem os bens «que forem para arrendar». Manda vender os moveis em hasta publica, d'onde concluem muitos que os immoveis tambem devem ser vendidos em praça. Alludindo aos bens de menores ( $(26)$, apenas preceitúa que só se alienem no caso de necessidade indeclinavel.

A torrente dos civilistas não alimenta a menor vacillação neste ponto: para a venda de bens de menor sob o patrio poder, absolutamente não é necessaria a hasta publica. Se para a transferencia de bens de orfams são requisitos essenciaes a justa causa, o despacho do juiz, a intervensão do tutor, e, como querem 
muitos, a hasta publica, para a venda de bens de menor sob o patrio poder só exige a lei a justa causa e o decreto judicial, sendo este algumas vezes dispensado, como se vae vêr.

Gomes, (Commentarii in Leges Taurinas, lex XLVIII, n. I \&), depois de expôr a opinião, professada por muitos, de que, havendo justa causa, o pae nem sequer precisa de licença do juiz para alienar bens dos filhos menores, : quia patria potestas plus debet operari et majorem effectum habet quam potestas tutoris, et quia lex multum confidit de patre», ensina que para maior segurança deve exigir-se o decreto judicial: sed his non obstantibus, ego teneo contrarium, imo quod requiratur, decretum et auctoritas judicis.

NAS Variae Resolutiones, de restitutione minorum, cap. XIV, n. I 3, aconselha de novo que se faça a alienação mediante autorisação judicial; porquanto deve ser precedida a alienação de justa causa, apreciada pelo juiz, como, por exemplo, a necessidade de pagar dividas, de alimentos, ou outra similhante: "quod debiet praecedere et interponi ex justa causa, puta aris alieni, alimentorum, vel ex simili causa». Verdade é que no mesmo numero i 3 faz uma limitação, que o inclúe no numero dos que hoje dispensam a propria autorisação judicial, exigindo unicamente à justa causa, necessidade, ou, pelo menos, utilidade da alheiação; visto como, accrescenta, só ao pae que é tutor, ou curador do filho emancipado, cumpre solicitar o decreto do: juiz, decreto que se dispensa, quando o pae é legitimo administrador e usufructuario, sendo esta a opinião commum dos doutores (ibi etiam communiter doctores).

Sabelli (Summa Diversorum Tractatuum, tomo I. ${ }^{\circ}$, alienatio, XXIII, n. 20) doutrina que a alienação dos bens do menor sob o patrio poder, quando se faz por justa causa, e em consequencia de um acto 
licito, dispensa quaesquer solemnidades peculiares, para ser valida: "alienatio rerum immobilium minoris valet sine solemnitatibus, quando fieret ex necessitate et consequentia actus permissi».

Pegas (Resolutiones Forenses, tomo 5. ${ }^{\circ}$, cap. 99, ns. $22,23,24$ e 25) reproduz um julgado, em que se decretou: " $O$ que tudo visto e o mais dos autos, disposição de diveito, e resoluçâo dos doutores, conforme a qual, havendo justa causa, pode o pay, ainda sim decreto do juiz, vender os bens immoveis dos filhos que tém em seu poder. . ficando os compradores mais seguros, intervindo a authoridade do juiz, que tem por si a presumpção de diveito, e fuz os contractos firmes, por ser injustiça que os contrahentes sejam enganados pelo juiz que lhes segurou a validade do contracto» etc., etc. A sentença foi confirmada nos seguintes termos: "Alienationem praecessit 'causae cognitio, et decretum judicis, suib cujus fide nefas foret emptorem decipi: confirmetur ergo sententia».

Macedo (Decisiones, decisio, XII) discute a questão de saber se o pae, em caso de urgente necessidade, póde alienar sem decreto judicial, e reproduz a distincção de Gomes (Antonius Gomesizes) entre a hypothese em que o pae é usufructuario e administrador dos bens do filho sob o patrio poder e a em que o pae é tutor do filho emancipado:

«Scio esse opinionem distinguentem inter casum quo pater agit tanquam filii familias administrator, de quo lex multum confidit, atque ita per se solum possit alianare, et casum quo agit tanquam emancipati tutor, de quo minor fiducia habetur, atque ita per se alienare nequeat». (n. 3). Termina aconselhando que se impetre a licença sem alludir á hasta publica (n. 6).

Sylva (Ad Ordinationes, liv. 3.; tit. $42, \S 20^{\circ}$ ) affirma ser opinião commum que o pae, legitimo admi- 
nistrador dos bens do filho menor, póde alienar os bens de raiz do filho, havendo causa necessaria, permittida pelo direito, sem dependencia de decreto do juiz: Secundum autem opinionem communem, pater legitimus administrator filii ex causa justa, et necessaria, et a jure permissa, "potest alienare bona immobilia fili minoris absque decreto judicis, et sine ejus authoritate» (n. $3 \mathrm{I}$ ).

Sylva se apoia em Olea, De Cessione furium, que no tit. II, Quaest. VI, n. 28, escreveu: Si vero flius in potestate sit, subdistinguendum est: an céssio ex justa causa, an vero sine justa causa fiat; si enim et legitima causa adsit, magis recepta et vera sententia est, posse parentem immobilia alienare sine decreto... Et transactionem a patre factam super adventitivis sine decreto validam esse. . Necessaria vero et legitima causá. non stante, non posset pater actionem ad immobilia cedere, nec immobilia alienare; et cessio, sive alienatio, sine decreto non subsistere».

Olea cita Pinelus (Avres Pinhel), que, Ad Constitutiones Cod. de Bonis Maternis, parte $3^{\text {a }}$, n. I9 e seguintes, estuda a nossa questão; e, depois de examinal-a com o maximo rigor, chega á conclusão de que, em regra, havendo necessidade, o pae póde alienar os bens do filho sob o seu poder, sem alludir á impetração do decreto judicial: "Constat igitur ex praedictis regulariter interdici patri alienationem adventitionum, excepta causa necessaria».

Gabriel Pereira de Castro, (Decisiones, decisio decima nona, n. 3) tambem se occupa com a nossa questão, ensinando que o pae, quando administrador dos bens dos filhos sob o patrio poder, póde alienar taes bens, desde que proceda sem fraude, e por justa causa: «ergo cum patri commissa sit potestas administrandi bona fliorum, imo et illi. liceat sine fraude ex 
causa legitima talia bona alienare. . adeo ut, non data fraude consilio vel re, teneat alienatio». Não exige a licença do juiz, desde que o pae proceda de bôa fé, e por necessidade. Todavia, lembra que alguns jurisconsultos julgam mais seguro obtêr a licença do juiz: "ubi securius tamem dicit quod adhibeatur judicis authoritas». Fundado na lição de Ayres Pinhel, e na pratica lusitana, Gabriel Pereira de Castro doutrina que, havendo bôa fé da parte do pae, e justa causa para a alienação, não é mister exigir o consentimento do filho, seja impubere ou pubere, porque, explica, os paes são os mais zelosos defensores dos bens dos filhos, as pessôas que mais cuidam das coisas pertencentes aos seus filhos, a cujo patrimonio estão ligados o interesse e o prejuizo dos mesmos paes: «remota fraude, quae semper videtur abesse in patre, respectu filiorum, supervacaneus videtur flii juvenis consensus, tam in prima quam in adulta et maiori aetate, cum parentes de rebus filiorum magis solliciti sint, et illis majori cura invigilent, in quibus etiam eorum. vertitur praejudicium, et ideo inutilis videtur fliorum consensus» (n. 4).

Mendes de Castro, no Tractatus de Bonis Liberorum, que se lê no fim da Practica Lusitana, parte segunda, de bonis adventitiis, n. I $2 \mathrm{I}$, reproduz a com. mum opinião dos doutores, que distinguem muito accentuadamente a alienação de bens de orfams da alienação de bens de menores sob o patrio poder. Se é administrador dos bens do filho menor, diz Mendes DE Castro, o pae póde alienar esses bens sem dependencia sequer de decreto judicial, desde que proceda com justa causa: «si admistrator est, alienare poterit». E logo adeante: "potest enim ut pater etiam res immobiles sine decreto alienare». Os proprios immoveis póde alienar sem decreto do juiz. A razão é que ha grande differença entre o poder do pae e as facul- 
dades do tutor: "quia potestas patris major est re filii, quam tutoris, vel curatoris, in re minoris». Nem se deve presumir que o pae alienè temeraria, ou inconsideradamente, os bens do filho, porquanto, além da affeição paternal, elle tem interesses ligados aos bens "do filho: «Nec enim praesumendum est res filii patrem ita temere alienaturum, cum maxime prater affectionem paternam commodum in re fili habeats.

Lовão começa, notando que a Ord., liv..$^{\circ}$, tit. $88, \S 60^{\circ}$, parece proibir ao pae toda especie de alienação dos bens adventicios do filho. Observa depois que a lei patria, de accôrdo com 'o direito romano, não póde ter esse sentido. Exceptúa quatro casos, em que ao pae é permittido alienar os bens do filho, inclusive os adventicios, sem necessidade sequer de decreto judicial: I. $^{3}$-quando os bens adventicios do filho foram transmittidos a este já gravados com dividas; $2 .^{\circ}$ - quando se faz necessario pagar os legados com que o testador onerou o filho-herdeiro; $3 .^{\circ}$-quando ha urgente necessidade de alimentos para o proprio filho, ou para o pae; $4 .^{\circ}$-quando os bens são onerosos, de qualquer modo damnosos. Em todos esses quatro casos, procedendo o pae com bôa fé, justa causa, sem dólo, ou fraude, com piedade paterna, são validas as alienações, sem dependencia do decreto judicial. Em todos os mais casos, é indispensavel o decreto judicial. (Notas a Mello, vol. 2.., pags. 97 a ro3).

Borges Carneiro assignala a distincção entre vendas de bens de orfams e venda de bens de filhos sob o patrio poder, e affirma ser opinião commum que o pae, legitimo administrador dos bens de raiz do filho menor, póde alienal-os, mesmo sem autoridade do juiz. (Diveito Civil, tomo 3.., §.239, ns. 44 e 45.)

Coelho da Rocha expõe a doutrina commum, a saber-..que o pae, para vender bens do filho sob o 
seu poder; precisa ser autorisado pelo conselho de familia (entre nós pelo juiz de orfams), e só deve alienar taes bens no caso de necessidade urgente, ou manifesta utilidade (Direito Civil, § 306).

LAFAYETTE julga necessario o consentimento do filho ou o decreto judicial, se o filho é menor, para o pae empenhar, hypothecar, ou alienar por qualquer titulo, o peculio adventicio do filho, salvo nos casos seguintes: a) para pagar dividas ou legados, de que viesse onerado o peculio; b) para provêr á propria subsistencia, ou á do filho, em falta de outros meios; c) quando os bens são de sua natureza susceptiveis de rapida deterioração; d) ou, sendo immoveis, não pódem ser, por estereis, convenientemente aproveitados. (Direitos de Familia, § г г6, C. III).

C. Bevilaqua baseado nas lições de Lafayetre e Pereira de Carvalho, tambem só requer a autorisação do juizo para o pae alienar o peculio adventicio do filho sob seu poder, repetindo que a autorisação é dispensavel em certos casos, já expostos por LовÃo, e aqui reproduzidos.

A doutrina ensinada pela torrente dos civilistas patrios nada mais é do que a lição de Godofredo (no Corpus Furis, Dionisir GorhoFredi), onde a nota n. 45 á Const. $8 .^{2}, \S 50^{\circ}$, De bonis quae liberis' in potestate, diz: Mobilia et immobilia onerosa et damnosa parens sine solemnitate potest z'endere.

A regra de direito patrio, em summa, é que, excepto os quatro casos mencionados, em todos os mais é licito ao pae vender os bens do filho sob o patrio poder sem necessidade de hasta publica, e sómente com licença do juiz, licença dispensada nos quatro casos alludidos.

Dr. Searo Sessa. 